\title{
Reversible solid-oxide cell stack based power-to-x-to-power systems: Comparison of thermodynamic performance
}

\author{
Ligang Wang, ${ }^{\mathrm{a}, \mathrm{b}, *}$, Yumeng Zhang ${ }^{\mathrm{b}, \mathrm{c}}$, Mar Pérez-Fortes ${ }^{\mathrm{a}}$, Philippe Aubin ${ }^{\mathrm{a}}$, Tzu-En Lin ${ }^{\mathrm{d}}$, \\ Yongping Yang ${ }^{\mathrm{c}}$, François Maréchal ${ }^{\mathrm{b}}$, Jan Van herle ${ }^{\mathrm{a}}$ \\ ${ }^{\text {a }}$ Group of Energy Materials, Swiss Federal Institute of Technology in Lausanne, Switzerland \\ ${ }^{\mathrm{b}}$ Industrial Process and Energy Systems Engineering, Swiss Federal Institute of Technology in Lausanne, Switzerland \\ ${ }^{\mathrm{c}}$ National Research Center for Thermal Power Engineering and Technology, North China Electric Power University, China \\ ${ }^{\mathrm{d}}$ Institute of Biomedical Engineering, National Chiao Tung University, Republic of China
}

\section{H I G H L I G H T S}

- A decomposition-based method for optimally deploying grid-balancing plants.

- Power-to-x-to-power pathways evaluated for $\mathrm{H}_{2}, \mathrm{CH}_{4}, \mathrm{CH}_{3} \mathrm{OH}$, syngas and $\mathrm{NH}_{3}$.

- Power-to-x efficiency (53-69\%) ranks as $\mathrm{CH}_{4}>\mathrm{CH}_{3} \mathrm{OH}>\mathrm{NH}_{3}>\mathrm{H}_{2}>$ syngas.

- X-to-power efficiency (66-80\%) ranks as syngas $>\mathrm{H}_{2}>\mathrm{CH}_{4}>\mathrm{CH}_{3} \mathrm{OH}>\mathrm{NH}_{3}$.

- Round-trip efficiency (38-48\%) ranks as $\mathrm{CH}_{4}>$ syngas $>\mathrm{H}_{2}>\mathrm{CH}_{3} \mathrm{OH}>\mathrm{NH}_{3}$.

\section{A R T I C L E I N F O}

\section{Keywords:}

Electrical storage

Power-to-x

Reversible solid-oxide cell

Ammonia

Methanol

Sector coupling

\begin{abstract}
A B S T R A C T
The increasing penetration of variable renewable energies poses new challenges for grid management. The economic feasibility of grid-balancing plants may be limited by low annual operating hours if they work either only for power generation or only for power storage. This issue might be addressed by a dual-function power plant with power-to-x capability, which can produce electricity or store excess renewable electricity into chemicals at different periods. Such a plant can be uniquely enabled by a solid-oxide cell stack, which can switch between fuel cell and electrolysis with the same stack. This paper investigates the optimal conceptual design of this type of plant, represented by power-to-x-to-power process chains with $\mathrm{x}$ being hydrogen, syngas, methane, methanol and ammonia, concerning the efficiency (on a lower heating value) and power densities. The results show that an increase in current density leads to an increased oxygen flow rate and a decreased reactant utilization at the stack level for its thermal management, and an increased power density and a decreased efficiency at the system level. The power-generation efficiency is ranked as methane (65.9\%), methanol (60.2\%), ammonia (58.2\%), hydrogen $(58.3 \%)$, syngas $(53.3 \%)$ at $0.4 \mathrm{~A} / \mathrm{cm}^{2}$, due to the benefit of heat-to-chemical-energy conversion by chemical reformulating and the deterioration of electrochemical performance by the dilution of hydrogen. The power-storage efficiency is ranked as syngas (80\%), hydrogen (74\%), methane $(72 \%)$, methanol (68\%), ammonia (66\%) at $0.7 \mathrm{~A} / \mathrm{cm}^{2}$, mainly due to the benefit of co-electrolysis and the chemical energy loss occurring in the chemical synthesis reactions. The lost chemical energy improves plant-wise heat integration and compensates for its adverse effect on power-storage efficiency. Combining these efficiency numbers of the two modes results in a rank of round-trip efficiency: methane $(47.5 \%)>$ syngas $(43.3 \%) \approx$ hydrogen $(42.6 \%)>$ methanol $(40.7 \%)>$ ammonia $(38.6 \%)$. The pool of plant designs obtained lays the basis for the optimal deployment of this balancing technology for specific applications.
\end{abstract}

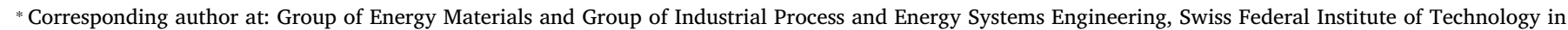
Lausanne (EPFL), Switzerland.

E-mail address: ligang.wang@epfl.ch (L. Wang). 


\section{Nomenclature}

Abbreviations

CE co-electrolysis

LHV lower heating value

MILP Mixed-integer linear programming

PowSto power storage

PowGen power generation

RSOC reversible solid-oxide cell

SE steam electrolysis
Mathematical symbols

$\dot{E} \quad$ energy flow

$\dot{W} \quad$ work flow

$\eta \quad$ efficiency

Subscripts

i mode

elec electrical

rt round-trip

\section{Introduction}

The critical challenges for future energy systems featured with the high penetration of variable renewable energy sources call for technological innovation on (1) the efficient storage of excess renewable power, (2) the integration of different energy grids and infrastructures (e.g., electrical, natural gas, transport fuel), and (3) the decarbonization of transportation fuels. Several electrical storage technologies are being actively developed, e.g., advanced batteries, super-capacitors, flywheels, redox flow batteries, superconducting magnetic energy storage, compressed air energy storage and electrolyzers [1]. Although some can reach a high round-trip efficiency, e. g., 80\% reported for a pumped hydroelectric storage and above $90 \%$ for lithium-ion batteries [2], the modestly-efficient electrochemical conversion can uniquely allow for converting excess renewable electricity to hydrogen and hydrogen-derived fuels, e.g., ammonia and carbonaceous fuels like methane and methanol [3]. The electrolyzer-based power-to-x links the electrical grid and the infrastructures of natural gas, transport fuels and chemical industry [4].

Compared to the established alkaline electrolyzer and the recent commercially-available proton exchange membrane electrolyzers, the solid-oxide electrolyzer, working at $650-850{ }^{\circ} \mathrm{C}$, can fundamentally achieve low resistance and high efficiency, and is expected to reach low capital investment costs without the use of precious and expensive metal catalysts [5]. More importantly, the unique all-ceramic material system allows, by nature, the same solid-oxide cell for a reversible operation of fuel cell and electrolysis, while the alkaline and proton exchange membrane technologies require different catalysts or active materials for each mode [6]. Thus, the solid-oxide cell can also be called reversible solid-oxide cell (RSOC) and enables a single RSOC-based plant with a common stack and balance of plant to work for power storage (PowSto) and power generation (PowGen) at different time periods. The excess renewable electricity is stored into chemicals in the PowSto mode, which can be either traded to other sectors or consumed in the PowGen mode. The switch between the two modes is enabled by changing on/off status as well as shifting the working loads of the units in the same plant. Such RSOC-based plants with the capability of electricity storage can provide flexibility to the power system. The reversible operation of the RSOC-based plants potentially enables to considerably enhance their cost-effectiveness [7], due to an increased annual utilization [7] and prolonged cell (stack) lifetime [8].

Solid-oxide fuel cells can operate with a range of chemicals, e. g., hydrogen, ammonia, syngas, methane, methanol, dimethyl ether, formic acid and gasoline, which, principally, can be synthesized in the PowSto mode by coupling power-to-hydrogen (steam electrolysis, SE) or power-to-syngas (co-electrolysis of steam and $\mathrm{CO}_{2}, \mathrm{CE}$ ) with existing chemical synthesis and upgrading processes. Therefore, various process chains (pathways) of power-to-x-to-power can be formed, e. g., powerto-methane-to-power, which includes power-to-hydrogen-to-methaneto-power (methane pathway via SE) and power-to-syngas-to-methaneto-power (methane pathway via CE). However, the selection of these pathways for practical applications depends on (1) their thermodynamic performances and (2) the characteristics of the target applications. This paper focuses only on the investigation of the first point: the thermodynamic performances with the consideration of the process chains of hydrogen, ammonia, syngas, methane and methanol.

In literature, the methane-fueled solid-oxide fuel cell systems are the most studied, which can reach electrical efficiencies of about $55-65 \%$ on the basis of the lower heating value (LHV) [9-11]. State-ofthe-art methane-fueled commercial systems can achieve an electrical efficiency of up to $65 \%^{1}$ (LHV) at $0.4 \mathrm{~A} / \mathrm{cm}^{2}$ without anode off-gas recirculation, which is one of the current technological trends aiming at increasing the system efficiency. The anode off-gas recirculation can increase the overall fuel utilization [12], reduce or even remove the dependency of fuel reforming on the external water supply [13-18]. It can also be applied to the systems with other chemicals. For example, methanol-fueled systems similar to the methane-fueled can achieve an LHV efficiency of 57\% [19]. The ammonia-fueled system has been emerging [20] after the pioneering work presented in Ref. [21], with an electrical efficiency of 53\% reported recently [22], which is almost the same as that of the hydrogen-fueled.

The power-to-hydrogen, methane and methanol systems have been conceptually compared considering heat cascade utilization based on similar stack operating points [3]. Particularly, the power-to-methane system has been studied intensively in Refs. $[23,24,4]$, which reveal the trade-off between the efficiency and the power density (investment costs) with the selected designs investigated in detail in Ref. [25]. The comparison of the SE and CE pathways highlighted that the CE extended the range of stack operation towards a low current density (e. g., $0.3 \mathrm{~A} / \mathrm{cm}^{2}$ ) with an enhanced system efficiency of over $80 \%$ (LHV) under elevated pressure. By employing a Rankine cycle for heat recovery, power-to-methanol and power-to-ammonia systems could reach efficiencies of over 65\% [26] and 70\% [27] (LHV), respectively, with the integration of biomass gasification [26-28].

The interests in the RSOC systems have increased along the last years, usually focusing on hydrogen and methane pathways $[29,7,30-32]$. However, the round-trip efficiencies reported for methane pathways of SE and CE differ significantly, e.g., over 70\% in Refs. $[29,7]$ versus $55-60 \%$ in Refs. [31,33]. The key issues that do not allow for round-trip efficiencies comparability are (1) the process concepts are calculated with a given system layout with specifically-designed heat exchangers and different stack operating conditions, (2) the performance indicators are evaluated with different definitions and methods, and (3) the analyses focus either on a technological aspect or on an application aspect, leading to non-optimal situations. Moreover, for the interest of the current work, there is a lack of references for the RSOC system pathways of methanol or ammonia.

This paper aims at laying a common ground, from both technological and application viewpoints, for the comparison of different RSOC systems (i. e., systems that synthesize and use different products). A two-step method for optimal deployment of the RSOC plants is

\footnotetext{
${ }^{1}$ https://www.solidpower.com/en/bluegen/.
} 
proposed with (1) a first complete screening of trade-off plant designs and (2) a subsequent optimal matching of selected plant designs for a specific application. The paper focuses on the first step: the optimal screening of plant design with respect to different objectives, which affect their investment and operating costs. The second step will be published in a follow-up paper.

This paper is organized as follows: In Section 2, the concepts of the process chains are introduced with the system boundaries described. Then, in Section 3, the methodology for the optimal deployment of such RSOC plants is proposed with the application-independent screening of plant designs, which is performed via a well-established multi-objective optimization method for the conceptual plant design. Then, the optimization results of all process chains are compared and discussed in Section 4 with a detailed exemplary analysis of the ammonia process chain. The conclusions are drawn in Section 5.

\section{Process chains and system boundary}

Considering the SE and CE options for power-to-x, seven process chains can be formed for the five chemicals (hydrogen, ammonia, methane, methanol and syngas):

1. Hydrogen pathway via SE: power-to-hydrogen-to-power

2. Ammonia pathway via SE: power-to-hydrogen-to-ammonia-topower

3. Syngas pathway via CE: power-to-syngas-to-power

4. Methane pathway via SE: power-to-hydrogen-to-methane-to-power

5. Methane pathway via CE: power-to-syngas-to-methane-to-power

6. Methanol pathway via SE: power-to-hydrogen-to-methanol-topower

7. Methanol pathway via CE: power-to-syngas-to-methanol-to-power

These process chains can be schematically represented by Fig. 1 with detailed flowcharts for both modes given in the supplementary data.

The stacks are operated with pure oxygen to avoid energy-intensive gas separation, which allows for efficient carbon or nitrogen management: The $\mathrm{CO}_{2}$ and $\mathrm{N}_{2}$ produced in the PowGen mode should be captured in high purity for the chemical synthesis in the PowSto mode. The capture is best enabled by the oxy-combustion of the off-gas by using the oxygen produced in the PowSto mode.

The management of the storage tanks depends on the applications and does not affect the thermodynamic performance of each mode. To ensure continuous operation, if there is a lack of chemicals to feed to one mode, the tanks will be considered to be filled by chemicals from the market; while if the tanks are full, the excess chemicals produced will be considered to be sold to the market.

The key system boundaries of both modes are the thermodynamic states of the interconnecting material flows, i.e., the temperatures, pressures and compositions of the chemicals flowing into and from the storage tanks. Thus, the power consumed to pressurize the chemicals for storage is considered within the boundaries of each mode. For the $\mathrm{CE}$ option, the syngas compositions are adjusted automatically following the procedure introduced in Ref. [24] to ensure a molar modular number $\left(\mathrm{H}_{2}-\mathrm{CO}_{2}\right) /\left(\mathrm{CO}+\mathrm{CO}_{2}\right)$ of 3 for the methane synthesis and the syngas pathway, and 2 for the methanol synthesis.

\section{Methodology and specifications}

\subsection{Decomposition-based approach for optimal plant deployment}

The deployment of a specifically-designed energy storage technology in a concrete application, i. e., to balance a specific profile of net electricity load, is usually optimized by solving a mixed-integer linear programming problem for its optimal sizing and scheduling, as described in, e. g., Ref. [34]. Additional complexity is added when aiming at optimizing the design of the technology as well for the considered application. A straightforward iterative method, outlined in Fig. 2a, is to couple the optimal plant design with the optimal sizing and scheduling. However, the optimal design of a single SOC system can be too time-consuming (up to days) due to heat integration and model complexity $[35,23,4,3]$, making such coupling hardly be applicable when involving a number of process chains and applications.

A general decomposition-based method originally proposed in this paper (Fig. 2b) suggests the de-coupling of the optimal plant design from the optimal sizing and scheduling. Such de-coupling is proposed on the basis that the thermodynamic performances of the dual-mode plant, e.g., system efficiency and power density of each mode, do not depend on the applications. This allows for generating an applicationfree pool (database) of the optimal plant design in one single optimization run. A set of the selected Pareto designs from the pool, which are featured with distinct thermodynamic performances, are then fed into the optimal sizing and scheduling step to identify the best-matching plant design as well as its size and schedule. Thus, the time-consuming optimal plant design step runs only once for each process chain to create the design pools, which facilitates the optimal matching of plant design with different applications.

The work presented here focuses on the step of the optimal plant design to create high-quality Pareto fronts with multiple design alternatives, highlighted by the red boxes in Fig. $2 \mathrm{~b}$.

\subsection{Approach of optimal conceptual plant design}

The optimal plant design named here remains at the level of conceptual design without a detailed design of the heat exchanger network. The target is to fast screen the plant designs by estimating their best thermodynamic performances considering heat integration. The conceptual plant design lays the basis for designing a detailed p\&id.

The iterative optimization procedure applied intensively to various power-to-x systems $[23,3,24,4]$ is extended in this work to consider the PowGen and PowSto modes simultaneously. As aforementioned, the switch of the two modes is enabled by changing the operation of the units in the same plant. It is assumed that the thermodynamic performances of the two modes are well estimated by simulating separate PowGen and PowSto flowsheets.

The iteration starts with the generation of design candidates, represented by technical specifications of the technologies considered. The flowsheets for each mode are simulated to obtain the energy and mass flows for heat integration as well as other necessary information to evaluate the performance indicators. The heat and mass flows are further structured as the input data of a unified mixed-integer linear programming (MILP) problem for multi-time heat/mass integration with utility selection and sizing. The solution of the MILP problem provides the sizes of all chosen technologies and utilities with classical

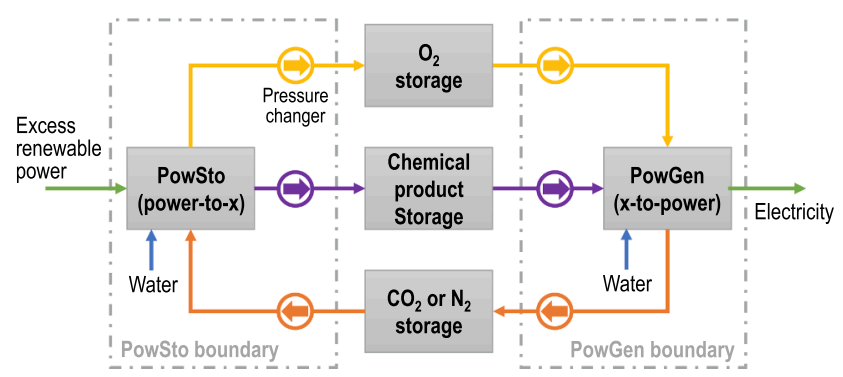

Fig. 1. The general schematic and system boundaries of the process chains. Detailed process flowcharts and descriptions are given in the supplementary data. The storage conditions are 200 bar and $30{ }^{\circ} \mathrm{C}$ for oxygen (pure), 60 bar and $30{ }^{\circ} \mathrm{C}$ for carbon dioxide (pure), 350 bar and $30{ }^{\circ} \mathrm{C}$ for hydrogen, 200 bar and $30{ }^{\circ} \mathrm{C}$ for nitrogen, 200 bar and $30{ }^{\circ} \mathrm{C}$ for ammonia (99 vol.\%), 240 bar and $40{ }^{\circ} \mathrm{C}$ for methane (98 vol.\%), and 1 bar and $40{ }^{\circ} \mathrm{C}$ for liquid water-methanol mixture (around 60 vol.\% methanol with no further upgrading considered). 
(a) Traditional method

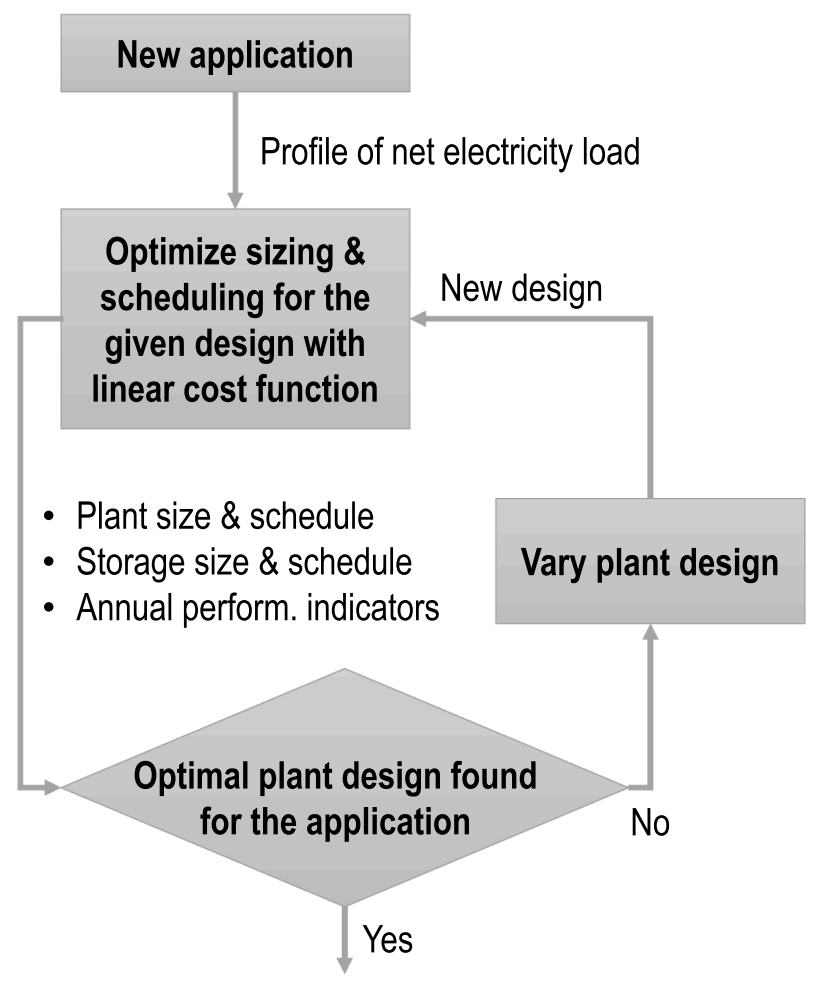

(b) Decomposition-based method

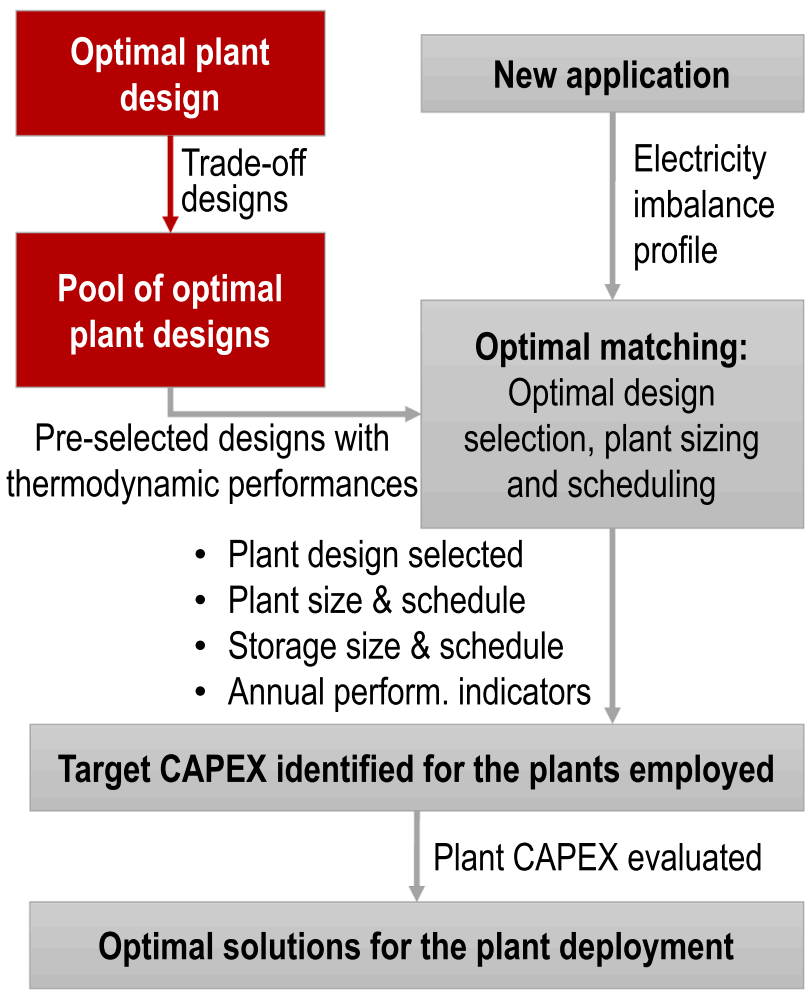

Fig. 2. Overall optimization methodology: (a) the traditional method, (b) the decomposition-based method.

hot-cold and grand composite tables, which can be graphically displayed to illustrate the cascade utilization of heat. Then, user-defined post-compute scripts are called to check the violation of practical constraints and to compute the objective functions considered. With multiple objective functions involved, queuing multi-objective optimizer serving as the master program manipulates the MILP problem as the slave program and controls the iteration. The high-quality cluster of Pareto-optimal designs obtained can reveal the trade-offs between different objective functions.

\subsection{Practical constraints}

Three practical constraints are considered for the conceptual plant design, as shown in Fig. 3:

- A maximum temperature gradient of the stack of $120{ }^{\circ} \mathrm{C}$ (considering no heat losses). The practical operation limits the temperature difference between the stack outlet and inlet below 80-100 ${ }^{\circ} \mathrm{C}$ [36], while the stack outlet temperature can be increased by $20-30{ }^{\circ} \mathrm{C}$ without heat losses, as experienced in the stack simulations for designing a pilot plant [37].

- Product purity

- Carbon deposition: After each process simulation, the chemical and phase equilibrium calculation will be performed via Cantera [38] for all the streams to detect carbon deposited in forms of graphite and diamond.

If these constraints are violated, specific penalties will be added to the objective functions.

\subsection{Objective functions}

Three objective functions are involved:

\subsubsection{Round-trip (energy) efficiency}

It is defined as

$\eta_{\mathrm{rt}}=\eta_{\text {PowSto }}^{i} \cdot \eta_{\text {PowGen }}^{i}=\left(\frac{\dot{E}_{\text {Powsto }}^{\text {fuel }, i}}{\dot{W}_{\text {PowSto }}^{\text {elec,tot }}}\right) \cdot\left(\frac{\dot{W}_{\text {PowGen }}^{\text {elec,net }}}{\dot{E}_{\text {PowGen }}^{\text {fuel, } i}}\right)$

where the $\dot{E}_{\text {PowSto }}^{\text {fuel }}$ is the energy stored in the chemical produced in the PowSto mode, while the $\dot{E}_{\text {PowGen }}^{\text {fue }}$ is the energy supplied by the chemical consumed in the PowGen mode. Both can be expressed in terms of lower heating value (LHV) or higher heating value (HHV), represented by $i$. The total electricity consumed in the PowSto mode $\left(\dot{W}_{\text {PowSto }}^{\text {electot }}\right)$ is from the stacks, compressors, fans, pumps and electrical heaters (if needed). The net electricity produced in the PowGen mode ( $\left.\dot{E}_{\text {PowGen }, i}^{\text {fuen }}\right)$ considers the consumption of the compressors, fans, pumps and electrical heaters (if needed).

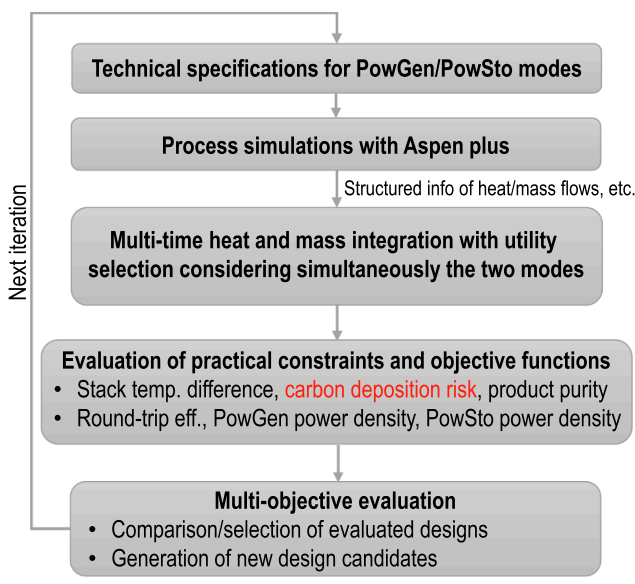

Fig. 3. Approach of optimal conceptual plant design. 


\subsubsection{PowGen power density}

It is calculated by levelizing the net power (electricity) produced by the PowGen mode with the total active cell area $\left(\mathrm{W} / \mathrm{cm}^{2}\right)$.

\subsubsection{PowSto power density}

It is calculated by levelizing the total power (electricity) consumed by the PowSto mode with the total active cell area $\left(\mathrm{W} / \mathrm{cm}^{2}\right)$.

The round-trip efficiency calculated here is the maximum one considering ideal heat integration without heat losses and DC/AC converter losses, which can account for up to 5-10 percentage points, as investigated in our previous paper [24].

\subsection{Models and decision variables}

Equilibrium-based thermodynamic models are sufficient for this paper. The quasi-2D electrolyzer model presented in Refs. [24,23] has been extended and further calibrated for the fuel cell mode. The electrode-supported plate cell stack operated at the atmospheric pressure is considered with a fixed inlet temperature of $680{ }^{\circ} \mathrm{C}$. The operating variables of the stack are listed in Table 1 , which are common for all process chains. Based on practical experiences, the oxygen inlet flow rate is limited to $50 \mathrm{sccm} / \mathrm{cm}^{2}$ (standard cubic centimeter per minute per square centimeter) for the electrolysis mode and $80 \mathrm{sccm} / \mathrm{cm}^{2}$ for the fuel cell mode.

The chemical synthesis processes in the PowSto mode are given in the supplementary data based on Refs. [3,28] for the methane and methanol synthesis, and Ref. [27,39] for the ammonia synthesis (Haber-Bosch process). For the PowGen mode, the chemicals can be reformed (cracked) internally in the stack or externally in a separate reactor; however, in this paper, internal carbonaceous-fuel reforming is only considered possible for methane, and an external reactor is considered for methanol and ammonia. The related decision variables and specifications of the chemical reactors are listed in Table 2.

Utilities are needed to close the energy balance of both modes. For hot utility, only electrical heating is considered; while lake, river and a refrigeration cycle with a coefficient of performance of 2.7 are considered as possible cold utilities.

\section{Results and discussion}

The detailed discussion of all process chains is presented in the supplementary data. Note that carbon deposition is detected in all simulations of the PowSto mode of the methanol pathway via $\mathrm{CE}$, in which the critical stream is the syngas (modular number of 3) entering the methanol synthesis reactor at $260{ }^{\circ} \mathrm{C}$ and 70 bar. Therefore, this process chain is not further discussed.

Below, the ammonia process chain is first taken as an example to illustrate the typical findings. Then, the performances of all process chains are compared intensively in terms of efficiency (based on the
Table 2

Design (operating) variables and specifications of chemical processingand synthesis processes.

\begin{tabular}{cccc}
\hline Variables or parameters & $\begin{array}{c}\text { Lower } \\
\text { bound }\end{array}$ & $\begin{array}{c}\text { Upper } \\
\text { bound }\end{array}$ & Fixed value \\
\hline $\begin{array}{c}\text { Methane/methanol reforming } \\
\text { temperature, }{ }^{\circ} \mathrm{C}\end{array}$ & 200 & 650 & - \\
$\begin{array}{c}\text { Steam-methane ratio of methane } \\
\text { reforming, }-\end{array}$ & 2.0 & 5.0 & - \\
$\quad \begin{array}{c}\text { Methanation pressure, bar } \\
\text { Methanation temperature, }{ }^{\circ} \mathrm{C}\end{array}$ & 1.1 & 30 & - \\
$\begin{array}{c}\text { Steam-methanol ratio of methanol } \\
\text { reforming, }-\end{array}$ & - & - & 290 \\
$\quad 1.0$ & 5.0 & - \\
$\quad \begin{array}{c}\text { Methanolization pressure, bar } \\
\text { Methanolization temperature, }{ }^{\circ} \mathrm{C}\end{array}$ & - & - & 70 \\
Ammonia cracking temperature, ${ }^{\circ} \mathrm{C}$ & 700 & - & 260 \\
Ammonia synthesis pressure, bar & - & - & - \\
Ammonia synthesis temperature, ${ }^{\circ} \mathrm{C}$ & Three stages $\left(495,473\right.$ and $\left.430{ }^{\circ} \mathrm{C}\right)$ \\
\hline
\end{tabular}

LHV), heat integration and power density.

\subsection{The ammonia process chain}

The trade-offs between the objective functions of the conceptual designs are given in Fig. 4a. An increase in the round-trip efficiency is followed by a decrease in the power densities (both PowGen and PowSto). The round-trip efficiency falls within the range of $27-43 \%$ with power densities of $0.19-0.36 \mathrm{~W} / \mathrm{cm}^{2}$ (PowGen) and $0.30-0.90 \mathrm{~W} /$ $\mathrm{cm}^{2}$ (PowSto). The efficiency breakdown in Fig. 4b shows that the PowGen efficiency varies in a larger range (42-63\%) than the PowSto efficiency (61-69\%). The latter is higher mainly due to the better plantwise heat integration, discussed below in Section 4.2.

The trends of key influential variables leading to such trade-off are presented in Fig. 5. The current density is a dominating factor of efficiency and power density. As known fundamentally, the increase in current density enlarges the power density but leads to increased overpotentials, thus a reduced efficiency (Fig. 5a). The variation of the overpotential affects the heat released inside the stack and thus the stack temperature, which is mainly controlled by the oxygen-side flow, the utilization factor and chemical reactions occurring in the stack (as intensively discussed by the authors in Ref. [23,24]). Therefore, for both modes, the increase in current density (overpotential) leads to an increase in the oxygen-side flow rate (Fig. 5b) decrease in the reactant utilization (Fig. 5c), to carry additional heat out of the stack. The stack's thermal management ability determines the feasible range of current density. Considering the specifications in Table 1 , the current density reaches the maximum $\left(0.55 \mathrm{~A} / \mathrm{cm}^{2}\right.$ for PowGen and $0.90 \mathrm{~A} / \mathrm{cm}^{2}$ for PowSto), at which the oxygen inlet flow rates reach their upper bounds. A further increase in the current density leads to the stack outlet temperature beyond $820^{\circ} \mathrm{C}$, not feasible for practical operation.

Table 1

Design (operating) variables or specifications of the stack, common for all process chains.

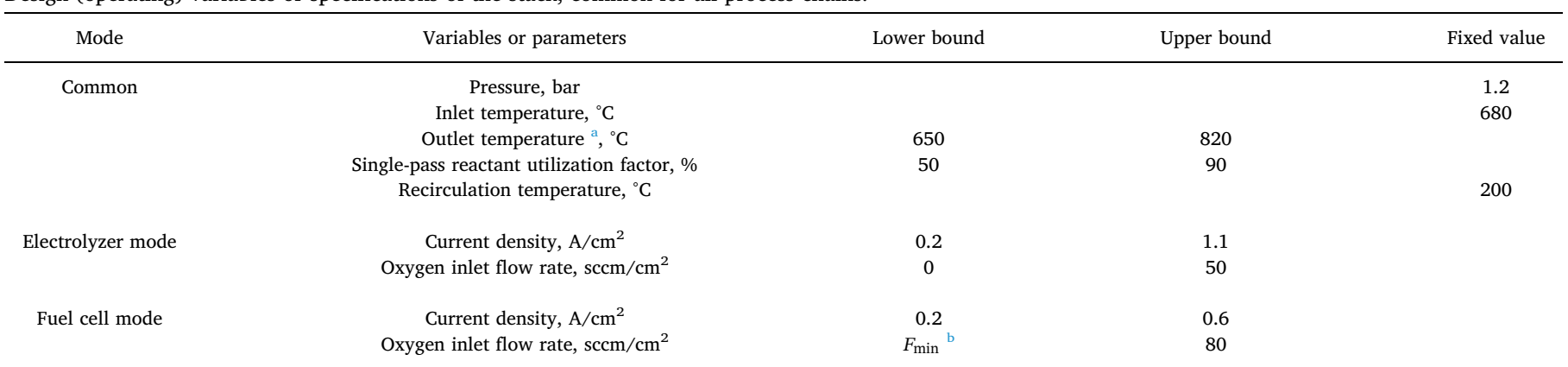

\footnotetext{
a Dependent variable, calculated by the stack model.

b Determined by the maximum oxygen utilization of $30 \%$.
} 


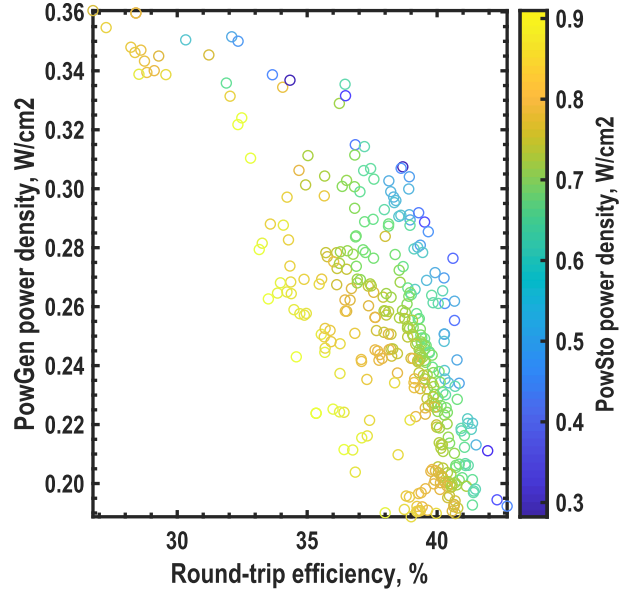

(a) Trade-off

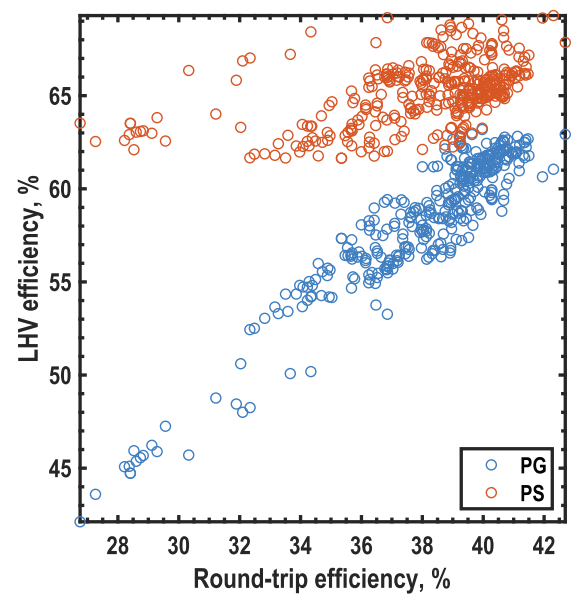

(b) Efficiency breakdown

Fig. 4. Trade-off designs and efficiency breakdown of the ammonia process chain.

For a given current density, the reactant utilization should be kept the highest possible if the stack's thermal management is sufficient. For the PowSto mode, with an increase in current density, the highestpossible utilization factor decreases down to its lower bound (50\%) to enable additional stack cooling by the unconverted reactants (Fig. 5b). This is the same for all process chains (see supplementary data).

For the PowGen mode, the utilization factor is reduced down to $70 \%$, while for all remaining process chains it is clustered at its upper bound ( $90 \%$, see supplementary data). The heat resulted from the overpotential of the hydrogen case can be fully managed by the oxygen flow. However, for the ammonia and carbonaceous-chemical cases, the overpotential is increased due to, e.g., reactant dilution, which asks for additional stack cooling ability. This task is best handled by the endothermic reactions occurring in the stack (internal reforming or reverse water-gas shift) for the carbonaceous-chemical pathways; while for the ammonia case in this paper, it can only be taken by the reduction of utilization factor. In reality with internal ammonia cracking, the utilization factor is also expected to stay at its upper bound.

\subsection{Performance comparison}

The efficiency of RSOC-based systems is the result of the interactions of electrochemical reactions, thermochemical reactions, and plant-wise heat integration, which are intensively discussed below with the comparison of efficiencies in Fig. 6 and heat integration in Fig. 7.

\subsubsection{Power generation efficiency}

As shown in Fig. 6a, the PowGen efficiency falls within the range of $51-60 \%$ for the hydrogen pathway, $42-63 \%$ for the ammonia pathway, $47-58 \%$ for the syngas pathway, $57-71 \%$ for the methane pathway, and $54-64 \%$ for the methanol pathway. The difference can be well understood from the PowGen efficiency formula in Eq. 1 in terms of the net power output and the chemical energy input.

Compared to the hydrogen pathway, at the same current density, the stack and net power outputs are reduced by using ammonia and carbonaceous chemicals, since the electrochemical reaction is worsened due to the dilution introduced by chemical processing. This is reflected by a drop of cell voltage with $\mathrm{H}_{2} / \mathrm{N}_{2}$ or syngas mixture: at $0.4 \mathrm{~A} / \mathrm{cm}^{2}$, $0.859 \mathrm{~V}$ (hydrogen), $0.837 \mathrm{~V}$ (syngas), $0.826 \mathrm{~V}$ (methane-derived syngas, over $80 \%$ externally reformed), $0.815 \mathrm{~V}$ (methanol-derived syngas, fully externally reformed) and $0.813 \mathrm{~V}$ (ammonia-derived mixture, fully externally cracked).

Compared to the hydrogen pathway, at the same current density, the chemical energy input is also reduced by using ammonia and carbonaceous chemicals, whose processing fundamentally enhances the fuel quality by endothermic thermochemical reactions:

$\mathrm{CH}_{4}(\mathrm{~g})+2 \mathrm{H}_{2} \mathrm{O}(\mathrm{l}) \rightarrow \mathrm{CO}_{2}(\mathrm{~g})+4 \mathrm{H}_{2}(\mathrm{~g}), \Delta H\left(25^{\circ} \mathrm{C}\right)=253 \mathrm{~kJ} / \mathrm{mol}$

$\mathrm{CH}_{3} \mathrm{OH}(\mathrm{g})+\mathrm{H}_{2} \mathrm{O}(\mathrm{l}) \rightarrow \mathrm{CO}_{2}(\mathrm{~g})+3 \mathrm{H}_{2}(\mathrm{~g}), \Delta H\left(25^{\circ} \mathrm{C}\right)=131 \mathrm{~kJ} / \mathrm{mol}$

$2 \mathrm{NH}_{3}(\mathrm{~g}) \rightarrow \mathrm{N}_{2}(\mathrm{~g})+3 \mathrm{H}_{2}(\mathrm{~g}), \Delta H\left(25^{\circ} \mathrm{C}\right)=92 \mathrm{~kJ} / \mathrm{mol}$

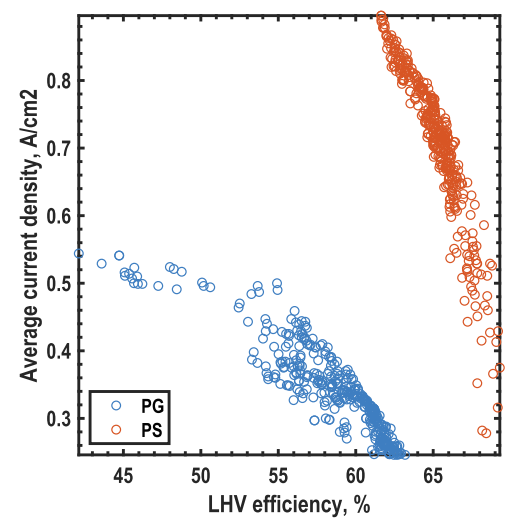

(a) Average current density

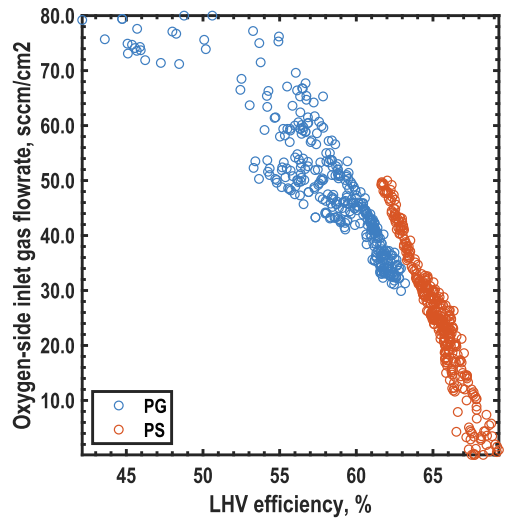

(b) Oxygen inlet flow rate

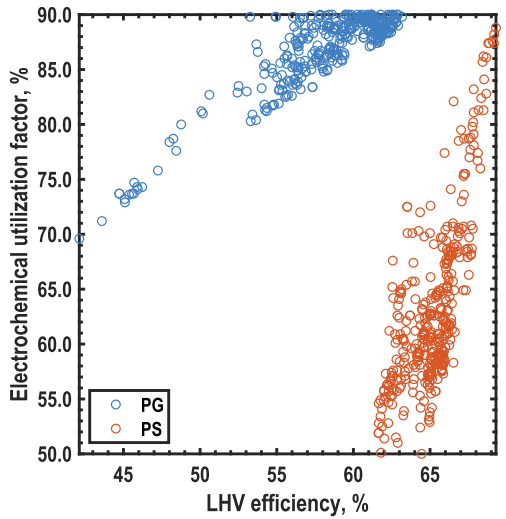

(c) Single-pass reactant utilization

Fig. 5. Key stack operating variables for the ammonia process chain. 


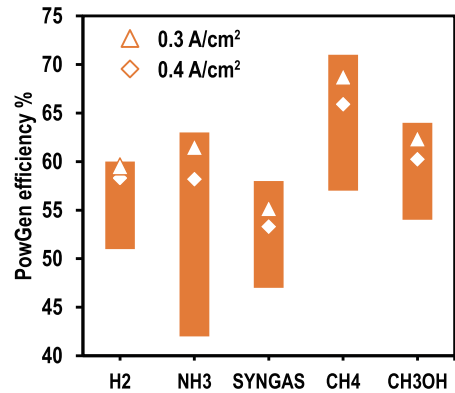

(a) PowGen efficiency

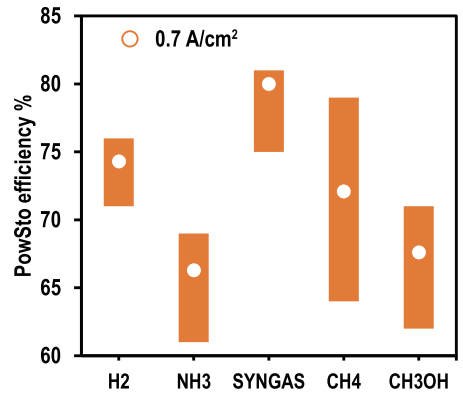

(b) PowSto efficiency

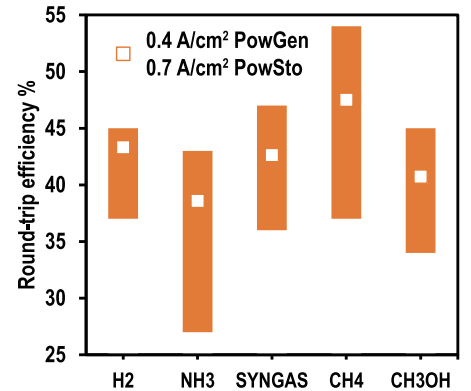

(c) Round-trip efficiency

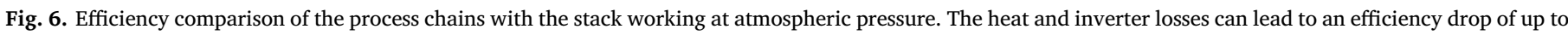

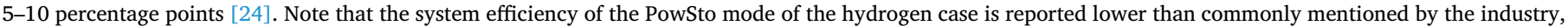
since the industrial applications usually employ waste heat from external processes for steam generation and thus need less electrical heating.

Therefore, the hydrogen produced has higher chemical energy than the raw chemicals. To produce $244 \mathrm{~kJ}$ hydrogen $(1 \mathrm{~mol})$ via Eq. 2-4, only $212 \mathrm{~kJ}$ from ammonia (2/3 mol), $201 \mathrm{~kJ}$ from methane (1/4 mol) and $213 \mathrm{~kJ}$ from methanol $(1 / 3 \mathrm{~mol})$ are needed, respectively, with the heat demand of $31 \mathrm{~kJ}, 63 \mathrm{~kJ}$ and $44 \mathrm{~kJ}$. This heat requirement can be fully satisfied by the plant-wise heat integration, since the overall PowGen modes of all process chains are strongly exothermic (Fig. 7a), due to the limit of practical reactant utilization. In general, the more heat recovered by the chemical processing, the less heat will be dissipated into the environment and the higher efficiency will be. The PowGen efficiency of the syngas pathway, however, does not benefit from such chemical processing.

In conclusion, compared to the hydrogen case, the deterioration of the electrochemical performance of ammonia and carbonaceous chemicals is overwhelming by the benefit of chemical processing coupling with heat integration; however, the ammonia case has to lower its reactant utilization (Fig. 5c) for a feasible design point. This results in the efficiency rank at the same current density: methane $>$ methanol $>$ ammonia $>$ hydrogen. The use of syngas as a raw fuel leads to a lower efficiency than the hydrogen case, due to an apparent drop in cell voltage but only a limited gain from heat integration.

\subsubsection{Power storage efficiency}

As shown in Fig. 6b, the PowSto efficiency falls within the range of $71-76 \%$ for the hydrogen pathway, $61-69 \%$ for the ammonia pathway, $75-81 \%$ for the syngas pathway, $64-79 \%$ for the methane pathway, and $62-71 \%$ for the methanol pathway. The performances of the hydrogen,

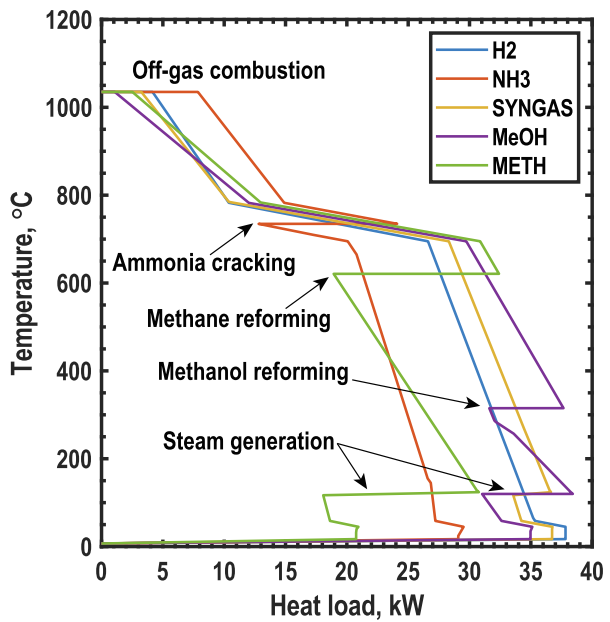

(a) PowGen mode at $0.4 \mathrm{~A} / \mathrm{cm}^{2}$ methane and methanol cases have been intensively discussed in Ref. [3]. In general, the efficiency depends mainly on the chemical synthesis reaction and plant-wise heat integration. The exothermic synthesis reactions dissipate a part of the chemical energy of hydrogen into heat and thus less chemical energy is stored in the form of the final product. For $244 \mathrm{~kJ}$ hydrogen $(1 \mathrm{~mol})$, the chemical energy stored is $212 \mathrm{~kJ}$ into ammonia (2/3 mol), $201 \mathrm{~kJ}$ into methane $(1 / 4 \mathrm{~mol})$ and $213 \mathrm{~kJ}$ into methanol (1/3 mol), respectively.

As illustrated in Fig. 7b, the heat-integration bottleneck is the steam generation. If the process heat of e.g. hydrogen and syngas cases is not sufficient for steam generation, electrical heating will be used and harms the efficiency. The syngas case employs co-electrolysis and requires less steam due to the presence of water-gas shift reaction in the stack, thus realizing a higher PowSto efficiency. However, the increased share of electrical heating in the total electricity consumption at a low current density can go up to $15 \%$ (Fig. 35 in the supplementary data), which results in the narrow ranges of their PowSto efficiencies. For the methane and methanol cases, a part of the chemical energy lost is compensated by the significantly improved heat integration: The electrical heating needed by the hydrogen and syngas cases is largely reduced by the exothermic methanolization reaction and even removed by the strongly-exothermic methanation reaction (Fig. 7b). Therefore, the syngas and hydrogen efficiencies are followed by those of the methane and methanol cases. The ammonia case shows the lowest PowSto efficiency, although (1) the ammonia synthesis only leads to a loss of chemical energy of hydrogen similar to the methane-SE case, (2) electrical heating needed is limited due to the enhanced heat integration.

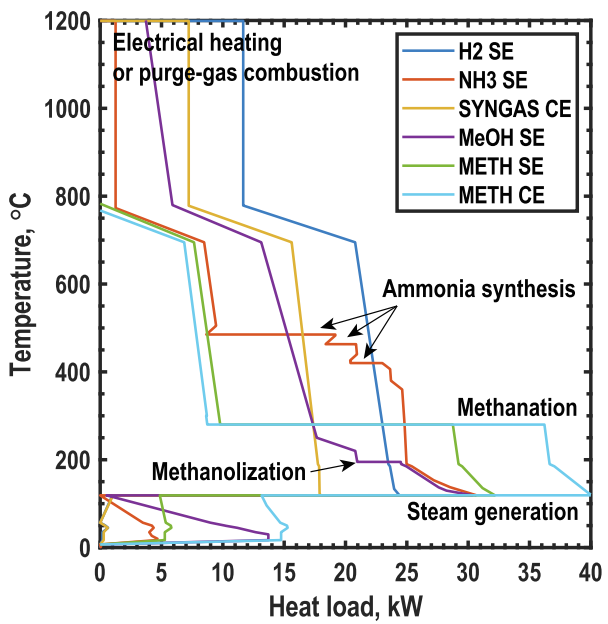

(b) PowSto mode at $0.7 \mathrm{~A} / \mathrm{cm}^{2}$

Fig. 7. Heat integration comparison with the stack working at atmospheric pressure. 
The major reason is the high electricity consumption of hydrogen compression for ammonia synthesis (200 bar), which can account for $7-8 \%$ of the total electricity consumption. Consequently, the rank of the PowSto efficiency becomes: syngas $>$ hydrogen $>$ methane $>$ methanol > ammonia.

\subsubsection{Round-trip efficiency}

Theoretically, any two design points of the PowGen and PowSto modes could be combined to form a design point of the RSOC system, given that a common balance of plant can be realized practically. Thus, with the separate PowGen and PowSto efficiencies discussed above, the rank of the round-trip efficiencies of all process chains can be well understood: methane $(37-54 \%)>$ syngas $(36-47 \%) \approx$ hydrogen $(37-45 \%)>$ methanol (34-45\%) > ammonia (27-43\%). For the design point with $0.4 \mathrm{~A} / \mathrm{cm}^{2}$ for the PowGen mode and $0.7 \mathrm{~A} / \mathrm{cm}^{2}$ for the PowSto mode, the round-trip efficiency is ranked as methane (47.5\%), hydrogen (43.3\%), syngas (42.6\%), methanol (40.7\%) and ammonia $(38.6 \%)$.

\subsubsection{Power density}

The power supply and demand of the RSOC systems define their interactions with the electrical grid. The power-density comparison of all process chains is given in Fig. 36 in the supplementary data. The PowGen power density, defined in Section 3.4, depends only on the stack power output and thus the cell voltage. For a practical range of the nominal current density $\left(0.3-0.4 \mathrm{~A} / \mathrm{cm}^{2}\right)$, the hydrogen pathway achieves the highest power density $\left(0.25-0.33 \mathrm{~W} / \mathrm{cm}^{2}\right)$. Due to reactant dilution, the power density is reduced when using carbonaceous chemicals $\left(0.23-0.31 \mathrm{~W} / \mathrm{cm}^{2}\right)$ and ammonia $\left(0.22-0.29 \mathrm{~W} / \mathrm{cm}^{2}\right)$.

The PowSto power density, defined in Section 3.4, depends on the electricity demand of the stack, gas compression and electrical heating. Due to the large need of electrical heating, the hydrogen and syngas cases reach a similar power density level $\left(0.88-0.90 \mathrm{~W} / \mathrm{cm}^{2}\right.$ at $0.7 \mathrm{~A} /$ $\mathrm{cm}^{2}$ ). The reduction of electrical heating of the carbonaceous chemicals and ammonia results in a lower power density within the range of $0.70-0.73 \mathrm{~W} / \mathrm{cm}^{2}$ at $0.7 \mathrm{~A} / \mathrm{cm}^{2}$.

\section{Conclusions}

Reversible solid-oxide systems are the key enablers to increase the penetration of variable renewable energy, and to allow for flexible coupling of different sectors as well as the decarbonization of transport fuels and chemical industry. A generic two-stage method for the optimal deployment of such reversible systems has been proposed by decomposing (1) optimal conceptual plant design and (2) optimal plant design selection and scheduling. This paper focuses on the optimal conceptual design of the dual-mode plants, which systematically screens the design of the process chains of hydrogen, methane, methanol, ammonia and syngas by varying the key operating variables of the stack and chemical reactors to create a pool of plant designs. The trade-offs between the round-trip efficiency and power densities are discussed and compared for all process chains based on an electrodesupported cell stack technology. Major conclusions with the efficiency based on a lower heating value are.

- The increase in the current density of either power-generation or -storage mode leads to a decrease in efficiency and an increase in power density of the system. For a given current density, the oxygen-side flow rate, utilization factor and internal thermochemical reactions are coordinated to achieve the highest efficiency with a feasible stack thermal management. In general, the increased current density calls for an increased oxygen flow rate and a decreased reactant utilization (not needed for the power generation mode).

- The power generation efficiency is ranked as methane (65.9-68.7\%), methanol (60.2-62.4\%), ammonia (58.2-61.5\%), hydrogen (58.3-59.5\%), syngas (53.3-55.2\%) at $0.4-0.3 \mathrm{~A} / \mathrm{cm}^{2}$, due to the interaction of electrochemical and thermochemical reactions. The electrochemical performance is worsened by the dilution of hydrogen; however, the chemical-to-hydrogen reformulation recovers process heat into the chemical energy of hydrogen, thus enhancing heat integration and mode efficiency.

- The power storage efficiency is ranked as syngas (80\%), hydrogen (74\%), methane (72\%), methanol (68\%), ammonia (66\%) at $0.7 \mathrm{~A} /$ $\mathrm{cm}^{2}$, due to the interaction of chemical synthesis reaction and plantwise heat integration. The electrical heating used in the hydrogen and syngas cases for the steam generation can be significantly reduced or even avoided by the heat released from the synthesis reactions, thus the chemical-energy loss in the synthesis reactions is largely compensated.

- The round-trip efficiency is ranked as methane $(47.5 \%)>$ syngas $(43.3 \%) \approx$ hydrogen $(42.6 \%)>$ methanol $(40.7 \%)>$ ammonia $(38.6 \%)$ at $0.4 \mathrm{~A} / \mathrm{cm}^{2}$ (power generation) and $0.7 \mathrm{~A} / \mathrm{cm}^{2}$ (power storage). The power generation power density achieves $0.22-0.33 \mathrm{~W} / \mathrm{cm}^{2}$ with hydrogen $>$ carbonaceous chemicals $>$ ammonia; while the power storage power density reaches $0.70-0.90 \mathrm{~W} / \mathrm{cm}^{2}$ with hydrogen $\approx$ syngas $>$ other carbonaceous chemicals and ammonia.

\section{Declaration of Competing Interest}

None.

\section{Acknowledgment}

L. Wang, M. Pérez-Fortes, P. Aubin and J. Van herle have received funding from the European Union's Horizon 2020 under grant agreement No 826161 (Waste2GridS), 735692 (CH2P), 731224 (BALANCE) and 826234 (Waste2Watts), and support from the Fuel Cells and Hydrogen Joint Undertaking, Hydrogen Europe and Hydrogen Europe Research. T.- E. Lin thanks the Young Scholar Fellowship Program by the Ministry of Science and Technology (MOST) in the Republic of China, under Grant MOST 108-2636-E-009-012. Y. Zhang and Y. Yang thank the financial support by the Science Fund for Creative Research Groups of the National Natural Science Foundation of China (No. 51821004).

\section{Appendix A. Supplementary material}

Supplementary data associated with this article can be found, in the online version, at https://doi.org/10.1016/j.apenergy.2020.115330.

\section{References}

[1] Venkataraman V, Pérez-Fortes M, Wang L, Hajimolana YS, Boigues-Muñoz C, Agostini A, et al. Reversible solid oxide systems for energy and chemical applications-review \& perspectives. J Energy Storage 2019;24:100782.

[2] Chen H, Cong TN, Yang W, Tan C, Li Y, Ding Y. Progress in electrical energy storage system: a critical review. Prog Nat Sci 2009;19(3):291-312.

[3] Wang L, Chen M, Küngas R, Lin TE, Diethelm S, Maréchal F, et al. Power-to-fuels via solid-oxide electrolyzer: operating window and techno-economics. Renew Sustain Energy Rev 0000 (0-0).

[4] Jeanmonod G, Wang L, Diethelm S, Maréchal F, et al. Trade-off designs of power-tomethane systems via solid-oxide electrolyzer and the application to biogas upgrading. Appl Energy 2019;247:572-81.

[5] Jacobson AJ. Materials for solid oxide fuel cells. Chem Mater 2010;22(3):660-74.

[6] Mougin J. Hydrogen production by high-temperature steam electrolysis. In: Compendium of hydrogen energy, Elsevier, 2015; p. 225-3.

[7] Wendel CH, Braun RJ. Design and techno-economic analysis of high efficiency reversible solid oxide cell systems for distributed energy storage. Appl Energy 2016;172:118-31.

[8] Fang Q, Packbier U, Blum L, et al. Long-term tests of a jülich planar short stack with reversible solid oxide cells in both fuel cell and electrolysis modes. Int J Hydrogen Energy 2013;38(11):4281-90.

[9] Braun RJ. Optimal design and operation of solid oxide fuel cell systems for smallscale stationary applications.

[10] Maréchal F, Leuenberger S, Membrez Y, Bucheli O, Favrat D, et al. Process flow 
model of solid oxide fuel cell system supplied with sewage biogas. J Power Sources 2004;131(1-2):127-41.

[11] Palazzi F, Autissier N, Marechal FM, Favrat D. A methodology for thermo-economic modeling and optimization of solid oxide fuel cell systems. Appl Therm Eng 2007;27(16):2703-12.

[12] Peters R, Deja R, Engelbracht M, Frank M, Blum L, Stolten D, et al. Efficiency analysis of a hydrogen-fueled solid oxide fuel cell system with anode off-gas recirculation. J Power Sources 2016;328:105-13.

[13] Peters R, Deja R, Blum L, Pennanen J, Kiviaho J, Hakala T. Analysis of solid oxide fuel cell system concepts with anode recycling. Int J Hydrogen Energy 2013;38(16):6809-20.

[14] Liu M, Lanzini A, Halliop W, Cobas V, Verkooijen A, Aravind P. Anode recirculation behavior of a solid oxide fuel cell system: a safety analysis and a performance optimization. Int J Hydrogen Energy 2013;38(6):2868-83.

[15] Torii R, Tachikawa Y, Sasaki K, Ito K. Anode gas recirculation for improving the performance and cost of a 5-kw solid oxide fuel cell system. J Power Sources 2016;325:229-37.

[16] Wagner PH, Wuillemin Z, Diethelm S, Schiffmann J, et al. Design and experimental realization of a steam-driven micro recirculation fan for solid oxide fuel cell systems. ECS Trans 2019;91(1):187.

[17] Wagner PH. Schiffmann J, et al. Theoretical and experimental investigation of a small-scale, high-speed, and oil-free radial anode off-gas recirculation fan for solid oxide fuel cell systems. J Eng Gas Turb Power.

[18] Wagner PH, Wuillemin Z, Constantin D, Diethelm S, Schiffmann J, et al. Experimental characterization of a solid oxide fuel cell coupled to a steam-driven micro anode off-gas recirculation fan. Appl Energy 2020;262:114219.

[19] Larose S, Labrecque R, Mangin PJ. Modeling of methanol-fueled sofc with anode offgas recycling for simplified system design. ECS Trans 2017;78(1):2581.

[20] Afif A, Radenahmad N, Cheok Q, Shams S, Kim JH, Azad AK. Ammonia-fed fuel cells: a comprehensive review. Renew Sustain Energy Rev 2016;60:822-35.

[21] Wojcik A, Middleton H, Damopoulos I, et al. Ammonia as a fuel in solid oxide fuel cells. J Power Sources 2003;118(1-2):342-8.

[22] Satomi E, Iwai H, Suzuki S, Koide T, Takahashi Y, Eguchi K. Development of ammonia-fueled sofc. ECS Trans 2017;78(1):2537-40.

[23] Wang L, Pérez-Fortes M, Madi H, Diethelm S, Maréchal F, et al. Optimal design of solid-oxide electrolyzer based power-to-methane systems: A comprehensive comparison between steam electrolysis and co-electrolysis. Appl Energy 2018;211:1060-79.

[24] Wang L, Rao M, Diethelm S, Lin T-E, Zhang H, Hagen A, Maréchal F, et al. Power-tomethane via co-electrolysis of $\mathrm{h} 2 \mathrm{o}$ and co2: The effects of pressurized operation and internal methanation. Appl Energy 2019;250:1432-45.

[25] Wang L, Düll J, Maréchal F, Van herle J. Trade-off designs and comparative exergy evaluation of solid-oxide electrolyzer based power-to-methane plants, Int J Hydrogen Energy 2019;44(19): 9529-43. special Issue on Power To Gas and
Hydrogen applications to energy systems at different scales - Building, District and National level. doi:https://doi.org/10.1016/j.ijhydene.2018.11.151.

[26] Zhang H, Wang L, Maréchal F, Desideri U, et al. Techno-economic optimization of co2-to-methanol with solid-oxide electrolyzer. Energies 2019;12(19):3742.

[27] Zhang H, Wang L, Maréchal F, Desideri U, et al. Techno-economic comparison of green ammonia production processes. Appl Energy 2019;114135.

[28] Zhang H, Wang L, Pérez-Fortes M, Maréchal F, Desideri U, et al. Techno-economic optimization of biomass-to-methanol with solid-oxide electrolyzer. Appl Energy 2020;258:114071.

[29] Jensen SH, Graves C, Mogensen M, Wendel C, Braun R, Hughes G, et al. Large-scale electricity storage utilizing reversible solid oxide cells combined with underground storage of CO2 and CH4. Energy \& Environ Sci 2015;8(8):2471-9.

[30] Mottaghizadeh P, Santhanam S, Heddrich MP, Friedrich KA, Rinaldi F. Process modeling of a reversible solid oxide cell (r-SOC) energy storage system utilizing commercially available SOC reactor. Energy Convers Manage 2017;142:477-93.

[31] Santhanam S, Heddrich MP, Riedel M, Friedrich KA. Theoretical and experimental study of reversible solid oxide cell ( $r$-soc) systems for energy storage. Energy 2017;141:202-14.

[32] Reznicek EP, Braun RJ. Reversible solid oxide cell systems for integration with natural gas pipeline and carbon capture infrastructure for grid energy management. Appl Energy 2020;259:114118.

[33] Santhanam S, Heddrich M, Riedel M, Friedrich KA. Process design study of reversible solid oxide cell (r-Soc) system for coupling energy storage and hydrogen economy supply chain. ECS Trans 2017;78(1):2925-32.

[34] Zhang Y, Wang L, Wang N, Duan L, Zong Y, You S, et al. Balancing wind-power fluctuation via onsite storage under uncertainty: Power-to-hydrogen-to-power versus lithium battery. Renew Sustain Energy Rev 2019;116:109465.

[35] Wang L, Yang Z, Sharma S, Mian A, Lin TE, Tsatsaronis G, et al. A review of evaluation, optimization and synthesis of energy systems: Methodology and application to thermal power plants. Energies 2019;12(73): 00. doi:10.3390/en12010073.

[36] de Avila Ferreira T, Wuillemin Z, Faulwasser T, Salzmann C, Bonvin D, et al. Enforcing optimal operation in solid-oxide fuel-cell systems. Energy 2019;181:281-93.

[37] Pérez-Fortes M, Mian A, Srikanth S, Wang L, Diethelm S, Varkaraki E, et al. Design of a pilot sofc system for the combined production of hydrogen and electricity under refueling station requirements. Fuel Cells 2019;19(4):389-407.

[38] Goodwin David G, Speth Raymond L, Moffat Harry K, Weber Bryan W. Cantera: An object-oriented software toolkit for chemical kinetics, thermodynamics, and transport processes. Zenodo 2018. https://doi.org/10.5281/zenodo.1174508. Version 2. 4.0 https://www.cantera.org.

[39] Flórez-Orrego D, Sharma S, de Oliveira Junior S, Maréchal F. Combined exergy analysis, energy integration and optimization of syngas and ammonia production plants: A cogeneration and syngas purification perspective. J Clean Prod $2020 ; 244: 118647$. 